\title{
Avatars of the tortoise: life, longevity and simulation
}

\author{
Darren Tofts \\ Swinburne University of Technology, Australia \\ dtofts@groupwise.swin.edu.au
}

\begin{abstract}
This paper explores the contemporary fascination with artificial life and simulation. The concept of artificial life has broadened it reach from a rarefied speculative discipline to a phenomenon in popular culture and a fertile trope within the electronic arts. From its representation in the cinema, to virtual pets and tamagotchis, to advanced digital art, the essay examines the category of "life" in the age of digital simulation. Questions to do with artificial life range from the representation or incarnation of our "real" selves as avatars in digital spaces (such as computer games), to popular, artistic and scientific attempts to simulate autonomous life forms. In the context of digital art, the essay critically engages with the work of Australian artist Troy Innocent, in particular with his most recent installation, Artefact (2001). In Artefact, Innocent actively investigates the digital investment of life in avatars as they operate in an interactive game environment. In this work, Innocent prompts an intriguing, if troubling, question, central to the overall interests of this essay: what, in the age of digital simulation, is not alive?
\end{abstract}

Keywords: artificial life, avatar, longevity, ontology of digital life, simulation.
This is an extremely intricate subject.

Charles $\mathrm{D}$ arwin, The origin of species

No one knows for certain, but it is thought these giant tortoises live over 200 years in the wild. By way of illustration, a fully grown giant tortoise from $M$ adagascar ( $G$. radiata) was presented to the Q ueen of Tonga by Captain Cook in the 1770s. Thistortoise died in 1966. It is entirely possible, on your visit to the Galápagos, that you may meet one of the same tortoises who greeted Charles D arwin a mere 161 years earlier perhaps the sow, patient one he rodelike a pony, whooping with joy.

http://www.terraquest.com/galapagos

\section{I want more life!}

Q uestions. When was I born? W hat is the nature of my being? H ow long shall I live? Such is the human condition. But what do such questions mean in an age of simulation, when life can be generated artificially, simulated in the binary code of the digital program?

In Ridley Scott's proto-cybercultural film Bladerunner (1982), there is a talismanic moment that provides some crucial insights into these questions. In a desperate attempt to forestall death, the uber-replicant Roy Batty confronts his maker, Eldon Tyrell. The moment is sublime, overwhelming, almost too much to bear, as Roy whispers, as a man meeting his God, the prodigal son before his father, "It's not an easy thing, to meet your maker". In this profoundly elegiac moment, the creature that is like a human, yet 'more human than human', confronts the fatal flaw that binds biological and 
artificial life in this dystopic world: life is shortlived and eventually you die. Batty's search for answers to the basic questions of his existence prompts him to confront the first principles of life: morphology, longevity, incept dates. For all his perfection as a cybernetic organism, Roy Batty, like his maker, was brought into being, will live and then die. Replicants are not made to last and when they die, they die for good. In this they are more human than machine. Just as technology has failed humans in this world of commerce, it fails replicants as well. Like his maker, Batty craves that essence yearned for by humans for millennia - morelife. But denied more life, he takes life, killing Tyrell in a suitably 0 edipal manner by putting out his eyes.

The replicants' dread of mortality and their implicit search for more life is dramatically figured in another poignant moment earlier in the film, in the very first question put to Leon Kowalski as he undergoes the Voigt-K ampff test. The aim of this test is to distinguish the replicant from the human by putting the subject under emotional stress. Leon is confronted with the hypothetical scenario of turning a tortoise on its back in the baking desert sun and watching it struggle for its life. The tortoise, emblem of long life, becomes in that moment a symbol of the fragility of life. Leon, imaginatively forced to watch its life extinguish without offering assistance, betrays who and what he is in his agitated resistance to the scenario he is asked to consider.

\section{I, avatar}

Pop cultural texts such as Bladerunner acutely draw attention to the question of temporality, to the dimensions of life, artificial or organic. They also prompt questions to do with the relationship between longevity and ontology. Is there a correlation between long life and materiality, between longevity and form? Perhaps more persuasively than film, it is in the real $m$ of computer and video games that this question has been foregrounded in recent years. For quite a few years in the mid 1990s I played the shoot 'em up game D oom over a network. A part from the omnipresent ghouls and sprites with which I did battle, the other people with whom I was playing were al so represented as avatars on the screen. A part from the mute recognition of knowing that you were looking at a visual manifestation of a remote co-player, it was possible to communicate via text messages on the screen, which reinforced the sensation that in the simulated world of the graphic user interface, we all shared a vicarious, virtual presence. M ore than a flat representation, I was in the scene, sharing an environment as much as an adventure with other living people who, like me, were both here and there: in front of the computer as well as inside the game-space that the network made possible. This is the dialectic of the virtual. It is a post-C artesian split between the body and its avatars, the tracing of the corporeality of here in the digital materialisation of 'there'.

It was very exciting to know that I, too, was an avatar. In seeing them I was al so recognising what I looked like to them. This digital translation of embodied identity was a very dramatic instantiation of the breakdown of the boundaries between participation and spectatorship in computer-based interactives. The notion of the avatar as a digital persona or visualisation of the computer user, represents an important stage in the development of computer-based games, shifting the ontological field from being outside to inside the game or storyworld. H owever there is more at stake than digital aesthetics in this shift. As Brenda Laurel famously theorised in her landmark study of the poetics of immersive interactivity, Computersas Theatre (1991), the intervention into the gameworld as an active, engaged participant, represents a kind of agency. Agency, for Laurel, meant the ability to transcend rehearsed or programmed outcomes and affect outcomes that mattered and were determined by choice rather 
than algorithm. That is, agency was the ability to "act within a representation" (Laurel 1991 21, italics in original text).

Another way of thinking of such agency is that it represented another kind of experience, another experience of life, or, at least, 'dynamic behaviour' (to use C hristopher Langton's term) (Langton 1989 10-11). In this sense the elegant term avatar, derived from the Sanskrit avat_ra, is most apposite in suggesting the idea of a kind of transubstantiation, the incarnation of life in a different form. So while many people pondered the worth and relevance of such ultra-violent games, I preferred to think of D oom as a kind of parable about what was happening to received ideas to do with life and death in the age of cyberculture.

\section{Aliveness}

D oom crystallises an intriguing nexus of ideas to do with death and reanimation, digital avatars and longevity. It took me quite a while to work out that when you're dead playing D oom, you're not really dead: or rather, never really dead (the difference, as we shall, see, is more than inflection). By that I don't mean anything so facile as thinking that my on-screen avatar was somehow me, that reality and representation overlapped so literally (remember, the virtual is a dialectic, not a singularity). Despite the pronouncements of postmodern theorists such as J ean Luis Baudrillard, the map and the territory, for the time being anyway, don't adhere so neatly (although the ghost of what Jorge Luis Borges called 'exactitude in science' has al ways haunted the history of representation, from literature to $\mathrm{H}$ ollywood films: think of $\mathrm{H}$ amlet watching $\mathrm{H}$ amlet, or recall how M rs Vernon Presley wept in abject horror when Elvis' on screen character, Clint Reno, died at the end of Love M eTender?). Something strange happened when I finally worked out the toggle switch for reanimating myself. It was frighteningly obvious that the various chimeras I was trying to waste were coded to 're-spawn', but it was a real buzz to know that I too could come back to life having been vaporised by one of those plasma guns. But this wasn't really what took me by surprise. Something weird had entered my world. It was a metaphysical splinter that distracted me, a sudden recognition of the speed with which it had become second nature to think of life as artificial. At a time when the esoteric discipline of artificial life had even less of a public profile than it does now, electronic games were tampering with our understanding of what it means to be alive in an age of advanced cybernetic technology.

It's worth remembering that the academic discipline of artificial life, as we have come to understand it in the context of cyberculture, is not particularly old. Fascination with the concept in popular culture has endowed it with a misleading longevity, making the notion seem more a part of culture than it really is. In his seminal 1989 essay 'Artificial life', the computer scientist Christopher Langton outlined the key characteristics of artificial life. Central to this project was a fundamental departure from historical, essentialist thinking whereby life is a transcendent, quasi-mystical force. No longer a dualistic model that distinguishes the organic from the inorganic, the biological from the mechanical, Langton's singular concept of vitality, or aliveness, specifically and controversially separated the idea of life from its material properties:

Life is a property of form, not matter, a result of the organisation of matter rather than something that inheres in the matter itself.

(Langton 1989 41)

$R$ ather than a pure essence located within matter, life was a contingent property of formal processes, rules, codes and relations. Under such conditions, there was no ontological difference between artificial and organic life (which, it must be said, kind of begs the question of the continued use of the very term 'artificial' life). 


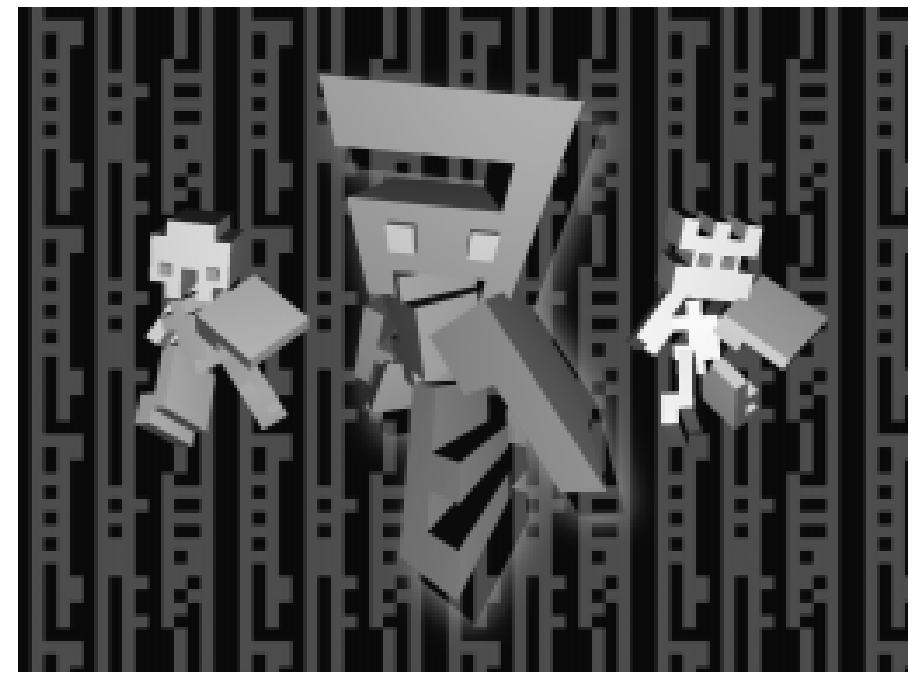

Figure 1. Troy Innocent, from 'Artefact'.

But the principles of artificial life articulated by Langton do themselves, it is equally worth noting, have an impressive longevity. Elements of the prehistory of artificial life have been articulated in a number of recent essays, notably by Evelyn Fox K eller and $C$ atherine Waldby. In a contextual rereading of M ary Shelley's Frankenstein, Waldby argues that the novel's portrait of monstrosity, of a living thing assembled out of dead flesh, must be understood in the light of thriving $19^{\text {th }}$ century explorations into 'technogenesis' - the idea that life could be made, as opposed to being found exclusively in the natural world (Waldby 2002). Similarly, Keller resuscitates a discredited $18^{\text {th }}$ century concept within molecular biology that posited life as the manifestation of the interaction of parts within the whole. Keller persuasively argues that such a perception of life in fact constitutes the basis of N orbert W iener's heralding of the cybernetic age in his principles of organisation and feedback (Keller 2002).

\section{Life, ab ovo}

Playing networked $D$ oom really made me think about the ways in which the simulated, immersive worlds of hyper-realistic graphics and vivid 'point of view' navigation, had started to define the psychopathology of a generation (in my revenant state playing D oom, I possessed an immortality that Roy Batty would kill for). This psychopathology is perhaps best represented in the tamagotchi phenomenon of the mid 1990s. First introduced by the Japanese company Bandai in 1996, tamagotchis - the word means 'love egg' - were a convergence of toy, computer game, artificial life simulation and morality play. Requiring constant interaction and nurturing, the tamagotchi creatures were designed to either thrive or die a premature death, depending on the kind of care they received. In this they revived the life lessons of the C abbage Patch dolls of the 1980s. The death of a $\mathrm{C}$ abbage Patch doll, which was provided for in the whole C abbage patch culture, was deemed to be a social good, an allegory that prepared children for the finality of death, whether it be of a beloved pet or a loved one. Simulated death in the tamagotchi industry, however, queered this allegory of mortality, preparing its users, as we shall see directly, for an altogether different conception of life and death.

\section{Just like a tamagotchi}

Even tamagotchis have their avatars, as evidenced in the growing popularity of cyber or virtual pets on the World W ideW eb (the Virtual pet home page goes so far as to describe this phenomenon as the 'virtual pet industry') (Virtual pet home page 2002). M any of these virtual pets are promoted as games or animations to interact with, as we would with any other digital media, such as the simulation game, Breeding gliders with cellular automata (Ventrella 2002). But many of them are defined quite seriously and explicitly as artificial life forms, not games. Creature Labs Cyberlife describes its 'N orns' as 'smart toys', drawing explicitly on biological rather than technological principles in their conception: 
Using the principles of biology, combined with sophisticated electronic sensor technology, we can create the embodiment of A-life in living toys. U sing these techniques, we build personable and intelligent robots and robotic toys, which can sense their environments, process the information they receive, and act on the results. (C reature Labs Cyberlife 2002)

The M opy Fish comes with a warning that it is, in fact, not a toy but "a pet fish developed to mimic the behaviour of a real parrot fish" (M opyfish 2002). We are advised, furthermore, that it is "alive and sensitive and you should, therefore, care for it just as you would a natural fish". O therwise, we are cautioned, it will become disinterested, sulk and eventually float to the surface, dead. There are also more sombre experiments in the creation of artificial life simulations, such as the D arwin Pond, which offers software for the generation of an "imaginary gene pool, a virtual world exhibiting the emergence of life-like behaviours". Life forms in the D arwin Pond, it would seem, evolve to accept the transience of life and the evolution of species, as its creator, Jeffrey Ventrella, advises that they "are $0 \mathrm{~K}$ with being killed - as long as you enjoy them when they are alive" (Ventrella 2002). A more satirical, though nonetheless instructive example, from the University of Sydney M edical Faculty, invoked the educational value of tamagotchis for $\mathrm{H}$ ealth Science students. In the Team 2000 Challenge: from cell to society, the cyber-pet is identified as a pedagogical tool that can promote "understanding of chronic health problems and their impact on the individual and their carers". Unlike an actual sick person, the tamagotchi "never dies", despite being stricken with multiple somatic complaints and dependent upon a range of medications. Student performance is measured in terms of how many times the tamagotchi dies in twentyfour hours (the penalty for excessive deaths being the student's immediate relegation to the Engineering Faculty) (T he clinical tamagotchi 2002).

\section{What kind of virtual caretaker will you be?}

As with the experience of D oom, then, it has become second nature to think of tamagotchi life forms as artificial. But with equal speed it has become second nature to think of such life as expendable and cheap. The end of the tamagotchi life-cycle is merely the opportunity to reanimate life, to commence the birth, life and death struggle all over again, perhaps many times within the same day. N ew life was merely a toggle away and far from mourning the death of a virtual cutie, children quickly realised that death was a temporary state, a pause that would last as long as it took to program another egg. In some cases, too, it was clear that kids would frequently pull the pin on intermediate life forms with which they had become bored and deliberately hatch a new egg to start afresh. It is quite an unnerving experience seeing kids telling their tamagotchis to shut up. Such impatient responses to the tamagotchi's persistent bleating and beeping testified to an implicit understanding of the aliveness of the creatures wanting to be nurtured. But impatience quickly deteriorated into neglect, as kids realised that it didn't really matter if the thing died, since it could be reanimated when they were more inclined to pay it attention ${ }^{1}$. As one distributor of virtual pets declares, "C yberPets are intelligent, clean, loyal, obedient... and they never die!"

(Phenomdesigns 2002).

I can testify to this as my daughter's Furby - an artificial life form reputedly capable of learning English through sustained interaction - stands mute in its carry-bag in her wardrobe in a permanent state of suspended animation. O nly coming to life briefly if it is moved accidentally or when she wants to show it off to a friend, it is actually more like a vampire than a life form, un-dead, neither living nor completely dead. In Bram Stoker's novel D racula (1897), Professor Van-H elsing describes the "un-dead" as "some dual life that is not as 


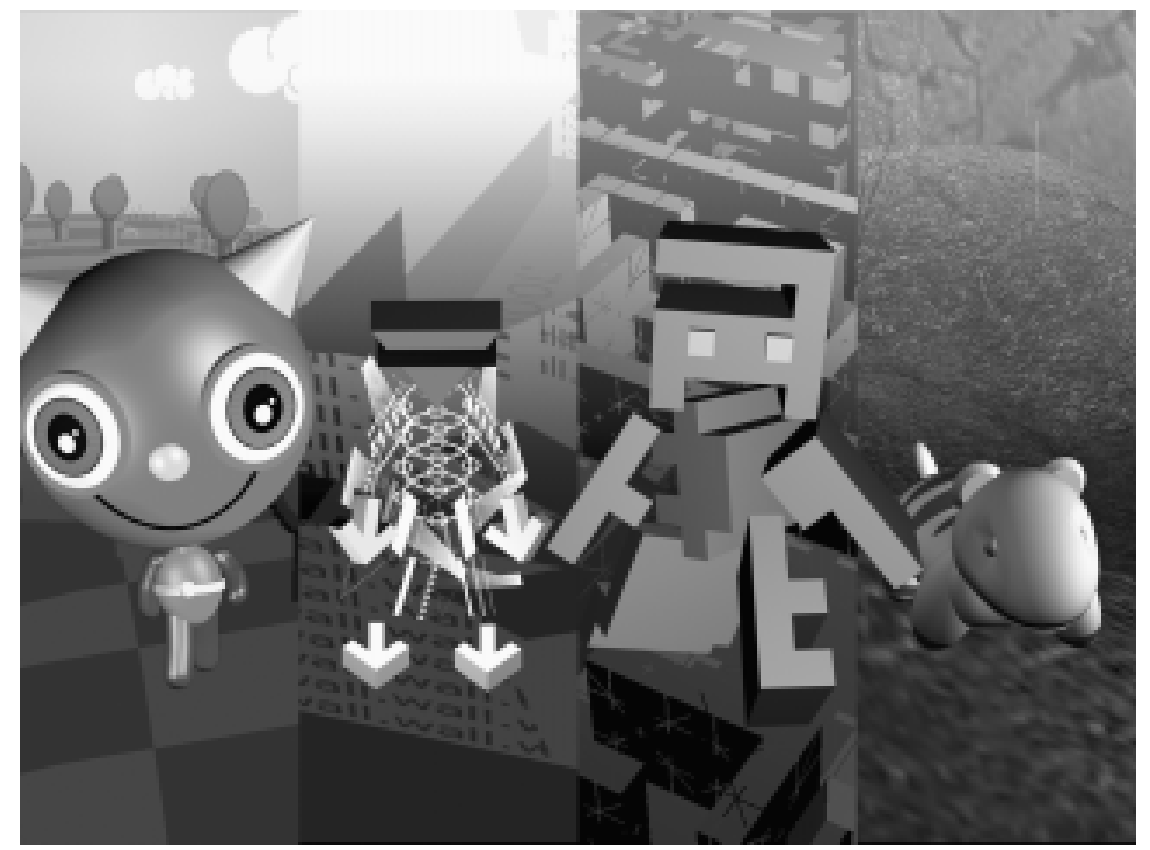

both poison and cure. $\mathrm{N}$ ot really alive, artificial life plays at being alive. N ever really dead, it reanimates indefinitely. The critique of the concept of vitality in the light of deconstruction has been particularly compelling, as Annemarie Jonson has noted. Jonson argues that the transposition of $D$ erridean notions of textuality into both the life sciences and discussions of artificial life have had profound implications for thinking about the very concept of life and, indeed, the concept of aliveness (Jonson 1999 54). The convergence in Jacques D errida's work of the concepts of life and writing has

Figure 2. Troy Innocent, from 'Artefact'. the common" (Stoker 1983 201). Struggling to define this contradictory, dual state of life for his bewildered colleagues, he is forced to concede that it is, in fact, no more mysterious than the mystery of life and longevity per se:

Can you tell me why the tortoise lives more long than generations of men... ?

(Stoker 1983 192)

Perhaps this gets us closer to the strange, perverse logic of artificial life, particularly as it is being understood by the post- $\mathrm{N}$ intendo generation. The concept of vitality, in the context of simulation, is highly ambivalent. It is not a dualist model of one thing or another, but rather it is one thing and the other, living and dead at one and the same time. In the game of simulated life and death, the beginning is not so much a genetic, originary act, an emergence, but rather the iteration or re-activation of a previous suspension. It is not the decisive organisation of form articulated by $\mathrm{C}$ hristopher Langton, but rather a persistent and undecidable deferral, a putting off for later. In this it is dissemination, différance, the pharmakon of deconstruction, problematised the appeal, within biology and the theory of artificial life, of the origin of life. D errida's critique of the program - genetic, digital, textual - as dissemination rather than organisation of presence, actively disrupts Langton's formalist conception of vitality, since, as D errida has written, the execution of the program is the mark of an absent presence, it is "differed-differing matter" (cited in Jonson 1999 58). Extrapolating from this, Jonson argues that

Once program, code and writing are thought of as difference... [the life and positival] sciences deeply metaphysical filiations are put into crisis. (Jonson 1999 57)

\section{The game of life}

I can imagine, sometime soon, in the near future, a spate of unreality TV shows for artificial life forms, the goal of which is to morph into our own world, rather like H omer does at the end of that 3D episode of The Simpsons. The grafting of the game show 
paradigm on to reality TV would have much in common with cyberspace and the evolution of digital life. Both involve a putative, though problematic incept time in which the conditions of life are set in motion. The dynamics of interaction are established within the hermetic world of human characters and digital entities alike, as well as the modes of interaction by which the external audience will engage with them. The rest is, well, simply a matter of the second law of thermodynamics. Unless there is constant input, from a variety of channels, the systems will break down. What began as a space of utopian possibilities declines into an entropic mess. These were the principles that, perhaps surprisingly, N orbert W iener drew on in developing his theory of cybernetics in the 1940s. But he also drew, even more surprisingly, on the game theory of John Von N eumann, who applied the idea of game play, as a means of forestalling entropy, to his design for the computer. Game-play is an agon, a strategic battle of wits in which two or more people, or artificial entities, develop strategic approaches to achieving certain ends. 0 ne of the key principles in game-play, a cybernetic principle that proved vital in the development of artificial life, was feedback.

In the context of game-play, feedback is a kind of memory system, the retention of information that can facilitate different outcomes when similar conditions are encountered. For example, a tamagotchi creature is programmed to remember to behave in certain ways when it is fed, when it is played with, etc. It is coded to do things in such a way that it appears to be responsive. $\mathrm{O} n$ the other hand, a reality TV contestant, presumably more alive than a tamagotchi, may act differently during the course of a day leading up to an eviction, based on the example of someone who was voted off the night before. This is a more dramatic form off feedback, since it involves the regulation of behaviour that is not programmed or based on a menu of expected outcomes. Rather, it is conditioned by the ability to act independently on information received from the environment and to regulate behaviour on the basis of that information. It is this type of feedback that computer scientists, such as M IT M edia Lab's Rodney Brooks, and media artists, such as Troy Innocent, are interested in exploring and bringing to our attention. Under such conditions, artificial life will perhaps develop a will of its own: or at least, to quote from Jurassic Park, it will "find a way".

\section{Life in the artefactual world}

Australian new media artist Troy Innocent has actively explored the possible ontology of digital life in a series of important works $s^{2}$. In Innocent's work we encounter a sustained attempt to push the boundaries of interactivity. Though not, however, the interactivity of the user with the world and its artificial life forms, but rather the interactivity of these entities with the user. In his 2001 work Artefact, Innocent deconstructed the video/computer game paradigm to reveal and foreground its implicit principles of interaction. But more importantly, in this work he actively examines the idea of what it means to converge the real and the digital, life and artificial life. The ontological convergence that I have discussed above, in relation to the experience of playing D oom in the light of Laurel's notion of 'agency', is dramatically highlighted in Artefact, but in reverse. Rather than feeling that we have become part of the virtual world, the entities of the virtual have in fact inhabited our world. In this, Artefact represents an ontological space that Innocent has evocatively called 'mixed reality'. The usefulness of this term lies in its departure from hackneyed concepts such as virtual, artificial or digital reality. While an apparently seamless convergence of worlds, there is still enough roughness around the edges to perturb and disrupt our understanding of what it means to be alive.

The various environments that constitute 


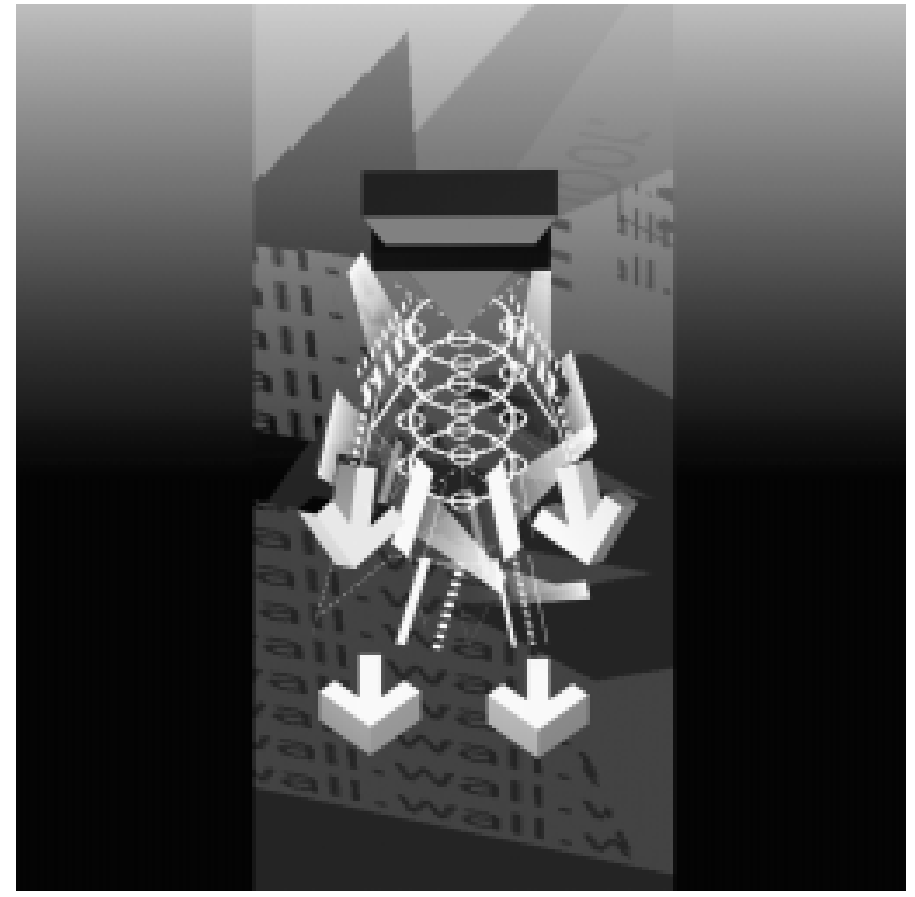

Figure 3.

Troy Innocent, from 'Artefact'.
Artefact are interconnected and intertextual, inviting different modes of response and interaction, that develop out of a familiarity with a community of entities and language of icons that filter throughout the gallery space. $M$ ixed reality is at once a space of reference for all of Innocent's work as well as an emblem of the activated environments that he has constructed in previous works (such as I conica 1999). It also cross-references, in sumptuous plastic and wood sculptures, the icons and entities in the game-space, Semiomorph.

Semi omorph draws on familiar modes of digital interactivity - joystick, fixed point of view of a mobile environment - to immerse the visitor in a simulated, immersive game-world of inclusive vision and surround sound within the physical space of the gallery. A world within a world, the fugitive presence of artificial nature is made manifest within the built environment of second nature. In this manifold space of mixed reality, neither world holds sway as the primary figure in a binary, hierarchical relation with the other.

Unlike I conica, Artefact is not an intelligent environment. H owever it cites and represents the cognitive behaviours associated with the former work and in this respect is a commentary on the very idea of an activated, responsive space. It cannily draws attention to our assumptions about artificial life, to the degrees of activity or inactivity in digital entities that our involvement in an artificial world precipitate. A work such as I conica presumes that we are aware that if we are sluggish and just going along for the ride, the entities will respond likewise. The activated, surveilled environment of Artefact takes this for granted as second nature. We are also reminded that we are dealing with reflexive entities and environments, in which the interplay between life and artificial life gives rise to a recursive cognition: we know that they know that we know that the more engaged we are, the more likely they will grow and evolve. In this Innocent's work strays into very contemporary thinking about the nature of complex systems. $\mathrm{H}$ is work gestures to the idea of an emergent universe, to use a term from chaos theory; a connected, networked space that becomes more and more complex over time. Artefact canvases the kind of thinking about complex systems that have been bundled under the rubric of the 'butterfly effect': the notion that a butterfly flapping its wings in Brazil will affect a hurricane in $\mathrm{H}$ awaii.

This is a constructed world, an artifact, without question, one that display Innocent's remarkable visual, sonic and architectural trademarks as a designer of virtual realms. An artifact, by definition, is something that is not found in nature. But artefacts can manifest within an environment - they are, then, instances of emergent behaviour. In the context of game-play, artefacts are subversive strategies, deliberate attempts to gain advantage or defeat an opponent. But they are also 'accentuated errors', incorrect, prompted behaviours mani- 
fested by entities in the game-world in response to our attempts to confuse and overwhelm them. W ithin the competitive interaction of game-play, unexpected, surprising forms of behaviour are artefacts, in a similar way to objects found at an archaeological dig. They require us to review what understanding we have formed of the space we are inhabiting and the culture we are getting to know. As we start this process of reflection, we realise that our thinking about the world in question, and the kinds of life within it, has changed. We start to think that this digital realm, this artificial reality, is an ecology, pixelated by living, responsive entities. W hat started out as a game has morphed into the discovery of a new world, an artefactual world.

From Artefact, then, we learn that artificial life is only partly to do with cute animals, cellular automata or blobs that that seem life-like, demanding to be fed, changed and medicated on demand. It is something that we are starting to realise is a parallel form of life in which computer generated entities - and this is the really scary bit - may develop the ability to continue to live, learn, remember and evolve, despite out interactions with them. Artefact samples those elements in Innocent's other works, notably I conica, that simulate the biological principle of homeostasis. Innocent is interested in simulating the fusion of his entities and their own environments, creating the dynamics by which his artificial life forms are more than avatars in a landscape. They dynamically interact with their ecology, responding, even mutating where necessary, to adapt to changed conditions. In this, to use a term of $H$ umberto $M$ aturana's and Francisco Varela's, they are 'self-making' ( $M$ aturana and Varela 1980), capable of reshaping themselves in response to their environment. Innocent's artificial life forms constitute part of a process whereby life is 'realised'. Another way of putting this, to invoke an idea discussed previously, is that his entities are active agents, causing outcomes that have not been predicted.

Q uestions. Given, as I have suggested, that artificial life never really dies, what, I wonder, happens to artefactual life forms such as G lypha or $\mathrm{M}$ t.ke.it when the computer is turned off? Where do they go? What happens if we ignore them and fail to interact with them? M oreover, why do we continue to privilege ourselves as $\mathrm{H}$ eisenbergian subjects affecting inexplicable changes in the observed? Why do we persist in thinking that we are the interactors, engaging with avatars like so many monkeys in a cage, so many tortoises on the Galapagos? H ow do we know that we, too, are not being observed, interacted with? H ow do we know that we remain unaffected by our visit to the gallery, that as the observed, we have not been touched in some profound way by acts of observation we don't even know are taking place?

These are the new questions to do with life and longevity in the age of simulation. If the evolution of Innocent's work is anything to go by, we can anticipate that in his next installation we, us, those outside the virtual world, will be the spectacle of a quizzical audience of mind children. Preoccupied with questions to do with the meaning of life, they will no doubt be piqued by the mere suggestion of our autonomy.

\section{Notes}

1 This curious dimension of the tamagotchi phenomenon was humorously picked up on by the authors of a book for parents on caring for orphaned tamagotchis effectively disowned by their children (C rimmins and $M$ aeder 1997).

2 For a detailed account of Innocent's work, see (Tofts 1999).

${ }^{3}$ Artefact was first exhibited at the M onash University Faculty of Art and D esign Gallery, M elbourne, 28 September - 3 N ovember, 2001. See www.iconica.org/artefact/ 


\section{References}

Creature Labs Cyberlife (2002) http:// www.creaturelabs.com/toys_index.htm. Accessed on $18 / 07 / 02$.

Crimmins, C. and M aeder, T. (1997) Tamagotchi egg: intentionally useless advice for the shell-shocked parent. Tor Books, N ew York.

Jonson, A. (1999) Still platonic after all these years: artificial life and form/matter dualism. Australian Feminist Studies 1429 47-61.

Keller, E. F (2002) M arrying the pre-modern to the post-modern: computers and organisms after W W II. In Tofts, D ., Jonson, A. and Cavallaro, A. (eds) (2002) Prefiguring cyberculture: an intellectual history. Power Publications, Sydney; M IT Press, Cambridge, M ass, pp. 52-65.

Laurel, B. (1991) Computers as theatre. AddisonWesley, Reading.

Langton, C. (1989) Artificial life. In Langton, C. (ed) Artificial life: the proceedings of an Interdisciplinary Workshop on the Synthesis and Simulation of Living Systems Addison-W esley, Reading, pp. 1-47.

M aturana, H. and Varela, F. (1980) Autopoiesis and cognition: the realization of the living. D. Reidel, D ordrecht.

M opyfish (2002) http://www.mopyfish.net. Accessed on $18 / 07 / 02$.

Phenomdesigns (2002) http:// www.phenomdesigns.com/phenom/moonlight/ cyberpet.htm. Accessed on 18/07/02.

Stoker, B. (1983) D racula. O xford U niversity Press, Oxford.

The clinical tamagotchi (2002) http:// www.med.usyd.edu.au/research/conf2000/ winner2.htm. Accessed on 19/07/02.

Tofts, D. (1999) Travelling to Iconica: the virtual worlds of Troy Innocent. In Tofts, D. Parallax: essays on art, culture and technology. Interface Books, Sydney, pp. 43-54.

Ventrella (2002) http://ventrella.com. Accessed on 18/07/02.

Virtual pet home page (2002) http:// www.virtual pet.com/vp/index.htm. Accessed on 19/07/02.
Waldby, C (2002) The instruments of life: Frankenstein and cyberculture. In Tofts, D ., Jonson, A. and Cavallaro, A. (eds) (2002) Prefiguring cyberculture: an intellectual history. Power Publications, Sydney; M IT Press, C ambridge, M ass, pp. 28-37.

D arren Tofts is $C$ hair of $M$ edia and Communications, Swinburne U niversity of Technology, M elbourne. He is the author, with artist M urray M CK eich, of M emory trade: a prehistory of cyberculture (1998) and Parallax. essays on art, culture and technology (1999). $\mathrm{H}$ is most recent book, edited with Annemarie Jonson and Alessio Cavallaro, is Prefiguring cyberculture: an intellectual history (Power Publications/M IT Press, 2002). 